\title{
Relações de Gênero na Educação Superior: uma análise do Programa Ciências sem Fronteiras
}

MELO, Hildete Pereira de 1

\section{Resumo}

Há um consenso mundial de que a educação é importante para o desenvolvimento econômico e social do mundo moderno e que esta reduz disparidades sociais e econômicas de um país ou região. No entanto, o desenvolvimento do processo educacional foi ao longo do tempo marcado pelo sexismo e relegou as mulheres a uma educação diferenciada por séculos. Esta diferença só foi, parcialmente, vencida pelas mulheres nos últimos 200 anos. Os feminismos têm desenvolvido a consciência de que a diferença que existe entre os sexos no espaço científico e tecnológico deve ser ultrapassada e que para isso a educação necessita integrar e visibilizar as mulheres nos feitos científicos e tecnológicos do mundo atual. Este estudo tem como objetivo analisar se amplificação da insurgência feminista do século XXI, clamando por igualdade entre os sexos e raças e se isso significou alguma mudança na definição das carreiras profissionais das meninas e moças nas duas últimas décadas. Assim, escolheu-se para avaliar este impacto o Programa Ciência sem Fronteiras, desenvolvido na segunda década deste século, pelo Estado brasileiro nas áreas das ciências exatas e tecnológicas.

Gênero. Ciências. Tecnologia. Carreiras profissionais. Política pública.

Gender Relations: an analysis of the Sciences without Frontiers program

\section{Abstract}

There is a worldwide consensus that education is important for the economic and social development of the modern world and that it reduces social and economic disparities in a country or region. However, the development of the educational process was over time marked by sexism and relegated women to a differentiated education for centuries. This difference has only been partially overcome by women in the last 200 years. Feminisms have developed the awareness that the difference between the sexes in scientific and technological space must be overcome and that education needs to integrate and make women aware of the scientific and technological achievements of today's world. This study aims to analyze whether the feminist insurgency of the 21st century has amplified, claiming equality between the sexes and races, and whether this meant any change in the definition of the professional careers of girls and women in the last two decades. Thus, the Science without Borders Program, developed in the second decade of this century, was chosen to evaluate this impact by the Brazilian State in the areas of exact and technological sciences.

\footnotetext{
${ }^{1}$ Doutora em economia, Professora da Universidade Federal Fluminense associada nível IV, hildete43@gmail.com.
} 
Gender. Science. Technology. Professional careers. Public policy.

\section{Introdução}

A ciência e a prática científica têm sido ao longo dos tempos marcados pelo sexismo e androcentrismo imperantes na sociedade. O influente filósofo inglês Sir Francis Bacon (1561-1626), no século XVII, declarava na Royal Society de Londres que esta sociedade científica devia "desenvolver uma filosofia masculina", por sua vez o prestigiado filosofo alemão, Immanuel Kant (17241804), no século XVIII ensinava que as pessoas que exerciam atividades intelectuais sérias deviam ter barba. E no século XX o sociólogo alemão George Simmel (1858-1918) afirmava que a objetividade era um atributo masculino. ${ }^{2}$

Mas, as mulheres participaram ao longo do tempo da criação da ciência, esta exclusão aconteceu no final do século XVII, quando a efervescência da primeira Revolução Industrial provocou dois movimentos que afetaram profundamente a vida das mulheres, por um lado à separação da produção e do consumo da orbita do espaço doméstico e a profissionalização da ciência. Segundo Schiebinger (2001) este duplo movimento que acentuou-se, sobretudo no século XVIII provocou a saída das mulheres dos espaços científicos e criação da figura da dona de casa.

Estes movimentos excludentes abrangeram todas as sociedades e a despeito da raça, identidade sexual ou mérito todas as mulheres, pela única razão que não o sexo - foram excluídas de estudarem nas universidades e faculdades e esta interdição vai até fim do século XIX. Estas proibições foram comuns a todas as mulheres, das ricas, proprietárias de terras, senhoras de escravos, escravas, brancas, negras, pobres. Todas foram excluídas dos direitos de cidadania até o século XX. Assim, a cultura patriarcal reduziu às mulheres a uma condição de inferioridade, que nem as poucas mulheres da elite europeia que conseguiram estudar escaparam deste estigma e também de forma contundente no seio da sociedade brasileira (ver SCHIEBINGER, 2001, p. 48; MELO \& THOMÉ, 2018, caps. 2 e 3).

Esta "invisibilidade" feminina relativa ao campo dos saberes científicos foi sempre desafiada por "algumas mulheres", como Hipátia (século $V$ da era cristã), em Alexandria/Egito, no século XI por Rosvita de Gandersheim, que assombrava os conventos com seus conhecimentos de matemática. E no século do iluminismo, emergiram outras mulheres Maria Gaetana Agnesi (1718-1799) na Itália, Emilie Du Chatelet (1706-1749) na França e já no XIX destacaram-se Ada Lovelace (1815-1852) e Sonja Kovalevsky (1850-1891).

2 Citado por Schiebinger, 2001, p.138. 
O levantamento destes nomes mostra que havia uma presença feminina e que estas não tiveram ausentes do desenvolvimento da matemática no mundo ocidental e no Brasil não foi diferente. A explosão dos cursos de Filosofia depois de 1930 faz emergir nomes femininos no desenvolvimento da matemática no país, como Marília Chaves Peixoto (1921-1961) e Elsa Furtado Gomide (19252013), reconhecidas como pioneiras no País.

A invisibilidade feminina também foi à tônica da construção das ciências física e da química. No século $X X$ as mais notáveis que não podem ser esquecidas foram Marie Curie (1867-1934) nos campos da Física e da Química, com a façanha de ter arrebanhado o Prêmio Nobel de 1903 e 1911 nessas Ciências. Sua filha Irene Joliot-Curie que também foi agraciada com Nobel de Química em 1935. E Rosalind Franklin (1920-1958), esta provavelmente a mais injustiçada das cientistas internacionais dos últimos 100 anos. Por que só a partir de sua pesquisa sobre cristalografia foi que James Watson, Francis Crick, Maurice Williams e ela própria descobriram a estrutura do genoma. No entanto, o reconhecimento foi sempre da trilogia masculina, eles foram quem receberam os louros por essa descoberta. ${ }^{3}$ Portanto, repetem-se os exemplos da matemática nos demais campos científicos, não foi e ainda não é fácil para as mulheres vencerem as barreiras impostas pela sociedade patriarcal.

Este simples resgate de algumas pioneiras ilustra apenas como na história da Ciência foi difícil para as mulheres venceram as barreiras impostas pelo patriarcalismo que as confinavam no espaço doméstico, locus privilegiado do papel feminino. E como essa perspectiva condicionou sua inferiorização nas esferas da vida pública, seja no mundo do trabalho, como no científico. Para Maruani et ali (1998) há uma transferência das características da divisão do trabalho da esfera doméstica para a vida profissional. E o campo científico é um exemplo contundente desta exclusão. Seja por que as instituições científicas podem encorajar ou desencorajar a participação feminina, ou dificultar a conciliação família e trabalho. $E$ isto acaba por provocar expulsão das mulheres dessas instituições, devido ao choque entre o círculo reprodutivo da vida e a carreira cientifica (LIMA, 2012).

Assim, a discussão feminista da ciência e da tecnologia tem desenvolvido uma crescente consciência da diferença que existe entre os sexos nestes espaços e esta ausência se expressa de forma contundente na escassez de figuras femininas na história da ciência. Resgatar estes nomes esquecidos é uma tarefa, como também empreender esforços pedagógicos, para motivar e integrar meninas e mulheres no processo de aprendizagem da ciência e da tecnologia.

3 O establishment científico afirma que isso se deu porque ela faleceu em 1958 e o Prêmio Nobel de Química foi concedido ao grupo em 1962. 
Como este processo de aprendizado está intimamente associado à educação e esta, por sua vez, ao desenvolvimento econômico e social do mundo moderno, o processo educacional tem sido apontado como uma das formas que pode possibilitar a redução das disparidades sociais e econômicas de um país/região e dos seres humanos. Desde a segunda metade do século XX que a literatura socioeconômica reitera a forte associação entre escolaridade e participação no mercado de trabalho. Comparativamente aos homens, no final dos anos 1990, as mulheres já apresentaram um avanço mais significativo em relação à escolaridade (BRUSCHINI, 2000; MELO, LASTRES, MARQUES, 2004).

Essa elevação da escolaridade feminina com a posse de um diploma universitário representa uma maior taxa de atividade no mercado de trabalho para ambos os sexos, pela valorização maior destes/as trabalhadores/as. Mas, para as mulheres este prêmio é ainda maior, porque a possibilidade de maiores rendimentos recompensa sua saída do ambiente doméstico. Pois, em 1999 as mulheres com diploma universitário apresentaram uma taxa de atividade de $82,3 \%$ enquanto a média feminina foi de $45,23 \%$ (População ocupada/População economicamente ativa metropolitana) ${ }^{4}$.

Claro, que no caso brasileiro o final do século XX e início do novo milênio assistiram a universalização do acesso à educação para ambos os sexos. Mas, os dados do Censo Demográfico de 2000 (IBGE) mostraram que os/as estudantes universitários brasileiros eram, naquele ano, de $56,5 \%$ do sexo feminino e $43,5 \%$ do masculino. Assim, na virada do século XXI as mulheres já haviam rompido com o passado e ingressado no mundo em que maiores oportunidades educacionais são oferecidas aos dois sexos (MELO, 2008, p. 67). No entanto, a carreira escolhida pelas meninas/mulheres se diferencia das masculinas. Suas escolhas são majoritárias naquelas carreiras próximas de sua socialização, não se escolhe o que se desconhece. Portanto, elas não escolhem as carreiras profissionais reconhecidas tradicionalmente como masculinas, tais como ciências exatas, engenharias e computação.

Vejam, em 2005 nos cursos de graduação presenciais do Brasil tínhamos apenas $20 \%$ dos estudantes de Engenharia e 19\% de Ciência da Computação do sexo feminino, enquanto em Letras as mulheres eram $80 \%$ e em Pedagogia $91 \%$ dos estudantes matriculados nestas graduações (MEC/Inep/Daes). Não se pode superar, do dia para noite, marcos culturais que impuseram para as mulheres restrições no universo de escolhas profissionais socialmente chanceladas. Por que os grupos sociais tendem a fazer escolhas baseadas na tradição e na experiência acumulada (SCHIEBINGER, 2001, MELO, 2008).

4 Ver sobre o assunto Melo, Lastres, Marques, 2004, p. 77. 
O avanço da educação no Brasil foi grande, nas últimas três décadas, e o país praticamente superou o analfabetismo; pois, a proporção de pessoas que não sabiam ler e nem escrever que tinha uma taxa de analfabetismo de $20 \%$ em 2005, viu esta cai para $15 \%$, em 2015. E em paralelo ampliou-se o número de estudantes no ensino superior. Analisando este progresso numa perspectiva de gênero nota-se que homens e mulheres ainda na segunda década do século XXI escolhem as carreiras de modo diferente. Como no passado mantiveram-se o predomínio masculino nas graduações de engenharias, ciências da computação e agrárias e as graduações de letras, serviço social, pedagogia, psicologia, enfermagem como carreiras femininas. Assim, a tradição demarcada pela divisão sexual do trabalho manteve-se e as escolhas das mulheres nas últimas décadas do século XX e nas primeiras do novo milênio concentram-se nas carreiras relacionadas aos cuidados e essa escolha acompanha toda a trajetória educacional feminina (MELO \& THOMÉ, 2018, cap. 5).

É preciso reconhecer que a educação e a prática científica inclusiva de gênero necessitam de uma política pública especifica cujo objetivo seja integrar meninas e mulheres nas atividades da ciência, tecnologia e inovação. Para isso é necessário estimular o desenvolvimento do campo de trabalho de gênero e enfoques feministas na análise dos preconceitos sexistas e androcêntricos da sociedade. Nos governos dos presidentes Luís Inácio Lula da Silva e de Dilma Rousseff uma política com este objetivo foi implementada, esta tinha como objetivo romper com estas barreiras - o Programa Mulher e Ciência.

Este programa foi uma iniciativa da Secretaria de Políticas para as Mulheres da Presidência da República (SPM/PR) na gestão da Ministra Nilcea Freire no primeiro governo do presidente Lula e com o sinal verde do Ministro da Ciência e Tecnologia Eduardo Campos, a Secretaria e o Ministério criaram o Programa em 2005. Este aglutinou os apoios do Conselho Nacional dos Direitos da Mulher, do Conselho Nacional de Desenvolvimento Científico e Tecnológico/ Ministério de Ciência, Tecnologia, do Ministério da Educação, ONU Mulheres, do Ministério do Desenvolvimento Agrário (MDA). Suas ações foram respaldadas pelos Planos Nacionais de Políticas para as Mulheres (PNPM, 2004, 20082011 e 2016) e representaram um compromisso assumido pela SPM/PR com as mulheres inseridas no sistema educacional e científico nacional e com toda a plataforma de luta das mulheres brasileiras que propugnavam por uma sociedade mais igualitária entre mulheres e homens.

As ações do Programa Mulher e Ciência não serão objeto de estudo deste trabalho, estas representaram um ambicioso custeio de pesquisas nas áreas de relações de gênero, raça e identidade presentes nas linhas de pesquisas de todo o campo científico e tecnológico. Por que o objetivo de suas ações abrangia o campo da produção do conhecimento, através dos núcleos e grupos de pesquisas presentes nas universidades brasileiras e nos institutos de pesquisa. Foram três Ministérios juntos que disponibilizaram os recursos financeiros para 
diversas chamadas públicas que de 2005 a 2012 com um aporte de 20,6 milhões de reais. Destinados à promoção de pesquisas que incentivaram o conhecimento nas áreas de relações de gênero, feminismos e mulheres e suas interseccionalidades com: classe social, geração, raça, etnia, sexualidade, todas temáticas contempladas pelas diversas edições do Plano Nacional de Políticas para as Mulheres.

Estas pesquisas tiveram impacto na disseminação da temática de gênero e de raça/etnia na sociedade brasileira e não se restringiu apenas ao campo das Ciências Humanas e Sociais Aplicadas, mas também a outras áreas do conhecimento. É preciso lembrar que pela primeira vez na história da ciência brasileira foram abertas linhas de financiamento para as questões das relações de gênero e raça. Outra ação significativa foi a criação do Prêmio "Construindo a Igualdade de Gênero" que distribuía prêmios para os estudantes de Ensino Médio, Graduação e Pós-Graduação de todo o País, com 10 edições realizadas ao longo destes anos, até 2015 e que até 2012 havia recebido mais de 24 mil trabalhos.

E na linha da preocupação da análise deste artigo em 2013, o Programa realizou uma Chamada Pública intitulada As Meninas e as Jovens Fazendo Ciências Exatas, Engenharias e Computação, no valor de 11 milhões de reais para atrair meninas e jovens do Ensino Médio e alunas de Engenharia em projetos de desenvolvimento científico e tecnológico que possibilitasse a quebra do padrão de escolhas tradicionais nas carreiras próximas ao papel feminino. Este programa tinha o apoio da SPM/PR, MCTI/CNPq e PR/PETROBRAS.

E por último, o Programa Mulher e Ciência foi o promotor da extensão da licença maternidade para as bolsistas de pós-graduação brasileiras, que posteriormente foi extensivo a toda a linha de financiamento científico dos órgãos governamentais: CNPq e CAPES. Esta breve síntese introdutória das políticas realizadas nos últimos anos permite elaborar a pergunta se o Programa Ciência sem Fronteiras, criado em 2011 foi de alguma maneira impactado por estas ações devido à insurgência das meninas/moças no cenário nacional.

\section{Um olhar de gênero no Programa Ciência sem Fronteiras}

O fio condutor de nossa análise do Programa Ciência sem Fronteiras, foi o olhar das relações de gênero sobre a distribuição das bolsas no ano de 2012 e verificar a participação do sexo feminino na aventura de cursar um período de estudos numa universidade estrangeira. Em áreas tão sensíveis as questões de gênero como a científica e tecnológica. Os micro dados que permitiram a abertura destes dados por sexo e área de estudos foram obtidos devido a atuação da autora como Coordenadora do Programa de Educação na SPM/PR, em 2013, num trabalho conjunto com a equipe do Programa "Mulher e Ciência" 
do CNPq. No entanto os resultados desta análise preliminar realizada no primeiro semestre de 2013 nunca foram divulgados.

O Programa Ciência sem Fronteiras foi criado em 2011, numa iniciativa conjunta dos Ministérios da Ciência, Tecnologia e Inovação (MCTI) e do Ministério da Educação (MEC), por meio de suas respectivas instituições de fomento - CNPq e Capes - e Secretarias de Ensino Superior e de Ensino Tecnológico do Ministério da Educação (MEC). O objetivo deste programa foi promover a internacionalização da ciência, tecnologia, inovação na sociedade brasileira através do intercâmbio de docentes e estudantes no âmbito da sociedade científica internacional.

O Programa tinha a duração de quatro anos, para os anos de 2012/2015 e previa distribui cerca de 101 mil bolsas para que estudantes de graduação e pós-graduação fizessem estágios em universidades e institutos de pesquisa no exterior. Também buscava atrair pesquisadores do exterior para o Brasil com o objetivo de desenvolver as áreas prioritárias definidas pelo Programa relacionadas ás áreas científicas e tecnológicas. Este Programa também contava com uma parceria da iniciativa privada; esta devia financiar, cerca de $26 \%$, das bolsas previstas nele.

O gráfico 1 mostra que este Programa no ano de 2012 apresentou a seguinte distribuição por sexo nas bolsas concedidas: $55,88 \%$ foram bolsas concedidas ao sexo masculino e $44,12 \%$ ao feminino e notem que há uma "quase" paridade entre os sexos no interior do programa. Qual o significado desta presença expressiva feminina neste Programa? Com esta preocupação abrimos os dados relativos à participação por sexo nos cursos de graduação presenciais e à distância para tentar compreender melhor a participação feminina na análise do Programa (gráficos 2 e 3).

\section{GRÁFICO 1:}

CNPq, Programa Ciência sem Fronteiras, distribuição de bolsas segundo sexo, 2012.

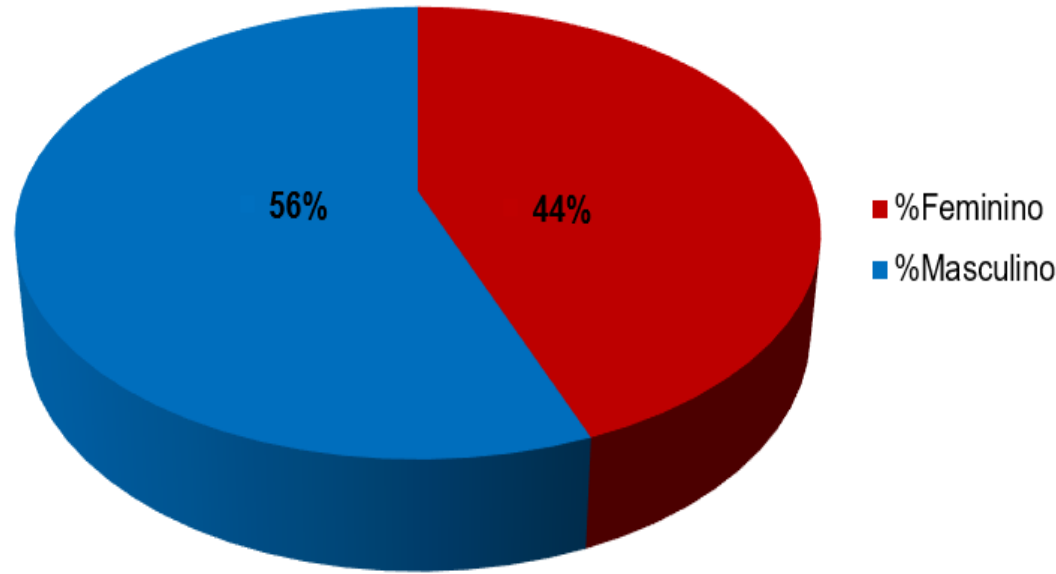

Fonte: CNPq, elaboração SAIAT/SPM, 2013. 
Seguramente o gráfico 1 traduz a entrada maior das mulheres nos espaços educacionais das últimas décadas, bem como de forma alentadora que timidamente novas escolhas estão sendo feitas pelas mulheres em relação as carreiras profissionais. Embora a inclusão das áreas de ciências biológicas e da saúde no Programa provavelmente tenha feito a diferença. Para entender melhor se a probabilidade de "novas" escolhas de carreiras estava em curso abriu-se os dados por sexo das matrículas dos cursos de graduação, segundo as modalidades de ensino presencial e a distância. Por que os cursos a distância tem um peso menor das carreiras profissionais relacionadas às áreas científicas e tecnológicas, embora tenha sido impossível abrir as informações do Programa segundo a origem dos cursos dos estudantes contemplados.

Assim, no gráfico 2 foi feita uma distribuição das matrículas por sexo nos cursos superiores presenciais do Brasil para o ano de 2011 e nota-se que as mulheres são 55,23\% destas matrículas (MEC/INEP, 2011) e no gráfico 3 foi feita à distribuição destas matrículas pelos cursos de graduação à distância. E de forma interessante esta taxa de participação feminina nas graduações a distância é bem superior: são $66,77 \%$ de taxa de participação feminina para uma participação masculina de $33,23 \%$. Fica evidente o significado da educação para as mulheres do Brasil e que elas mesmas em situações diferentes, provavelmente relativas à conciliação família e trabalho buscam a educação propiciada pelas graduações à distância como uma saída para o futuro. Todavia, abrindo as matriculas dos cursos de graduação presenciais por área de conhecimento (Gráfico 4) e observou-se que as áreas de Ciências Sociais Aplicadas e Humanas concentraram 33,07\% destas matrículas e estas áreas não estavam contempladas no Programa Ciência sem Fronteiras.

GRÁFICO 2

Matrícula nos Cursos de Graduação Presenciais do Brasil segundo o sexo, 2011.

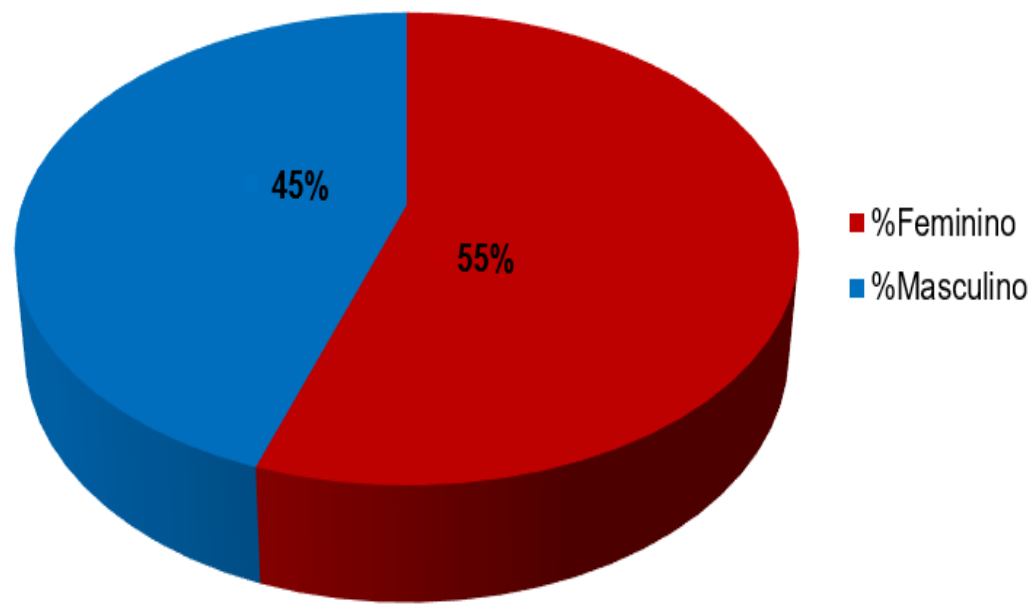

Fonte: MEC/INEP, elaboração SAIAT/SPM, 2013. 
Matrícula nos Cursos de Graduação à Distância no Brasil, segundo o sexo, 2011.

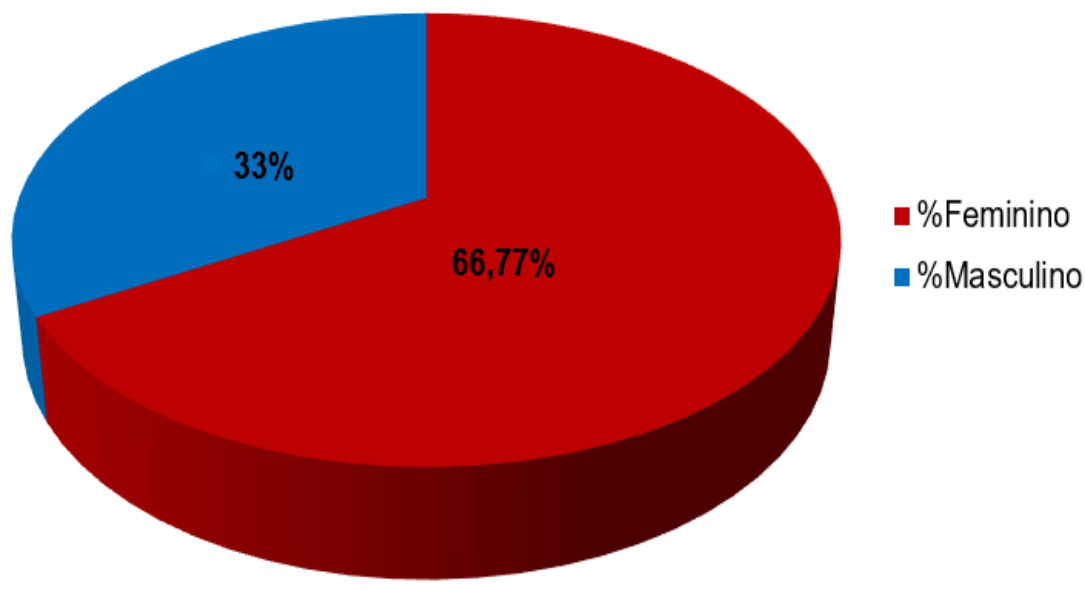

Fonte: MEC/INEP, elaboração SAIAT/SPM, 2013.

\section{GRÁFICO 4}

\section{Cursos de Graduação Presenciais no Brasil - Matrículas por Sexo e Área de Conhecimento, 2011.}

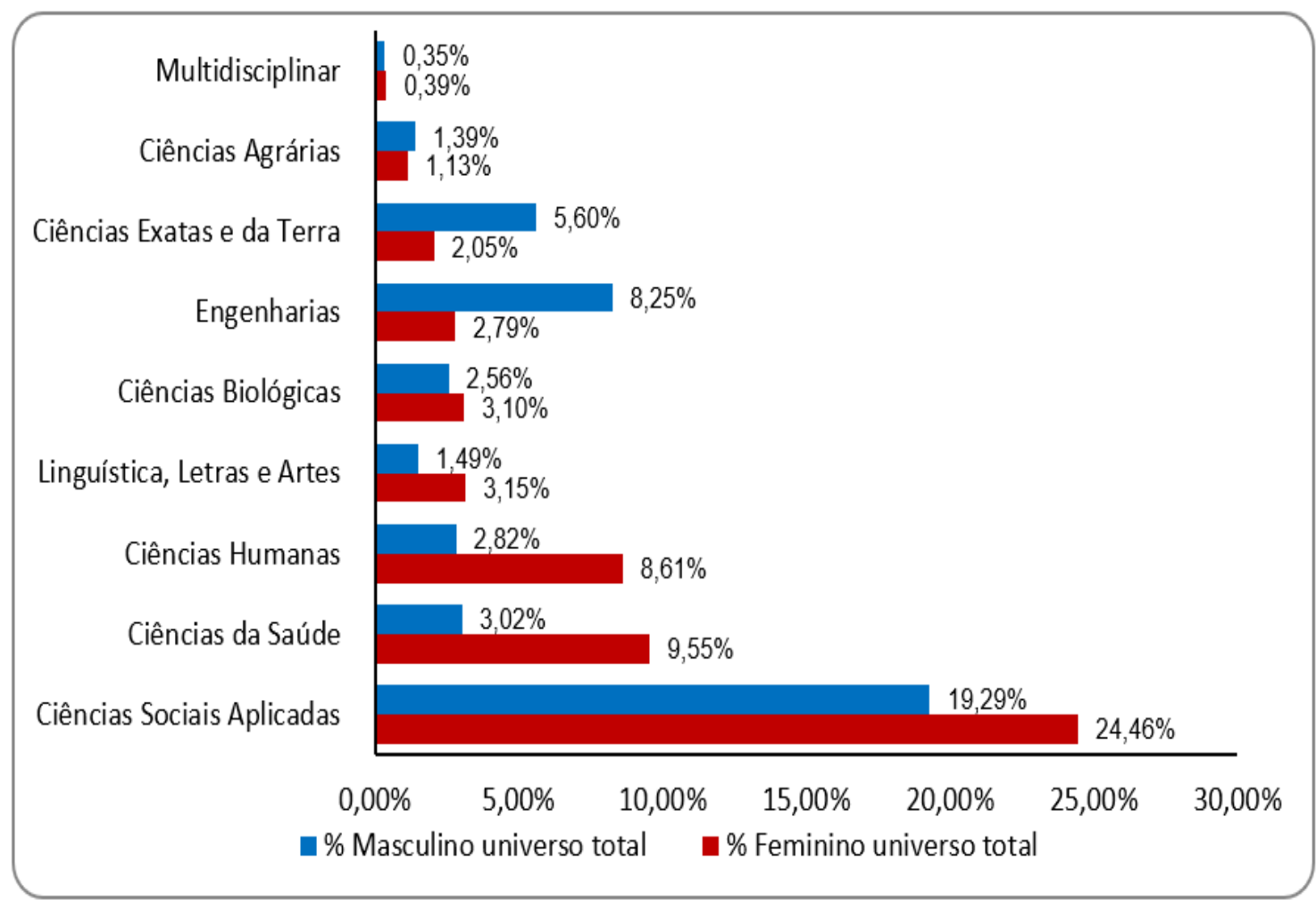

Fonte: MEC/INEP, elaboração SAIAT/SPM, 2013. 
Feito as considerações acima sobre a presença das mulheres no ensino superior brasileiro foram analisados o Programa Ciência sem Fronteiras pelas modalidades de bolsas: doutorado sanduíche, doutorado pleno, pós-doutorado, graduação sanduíche, treinamento especialista no exterior (empresa), jovem cientista (no Brasil) e pesquisador visitante (no Brasil) como mostra o gráfico $5 \mathrm{e}$ neste gráfico fica evidente a grande participação da modalidade bolsa graduação sanduíche no exterior $(81,65 \%)$, isto explica nossa preocupação com um olhar mais acurado sobre o ensino de graduação no País e suas relações com este Programa.

\section{GRÁFICO 5}

CNPq, Programa Ciência sem Fronteiras, segundo a distribuição de bolsas por modalidades, 2012.

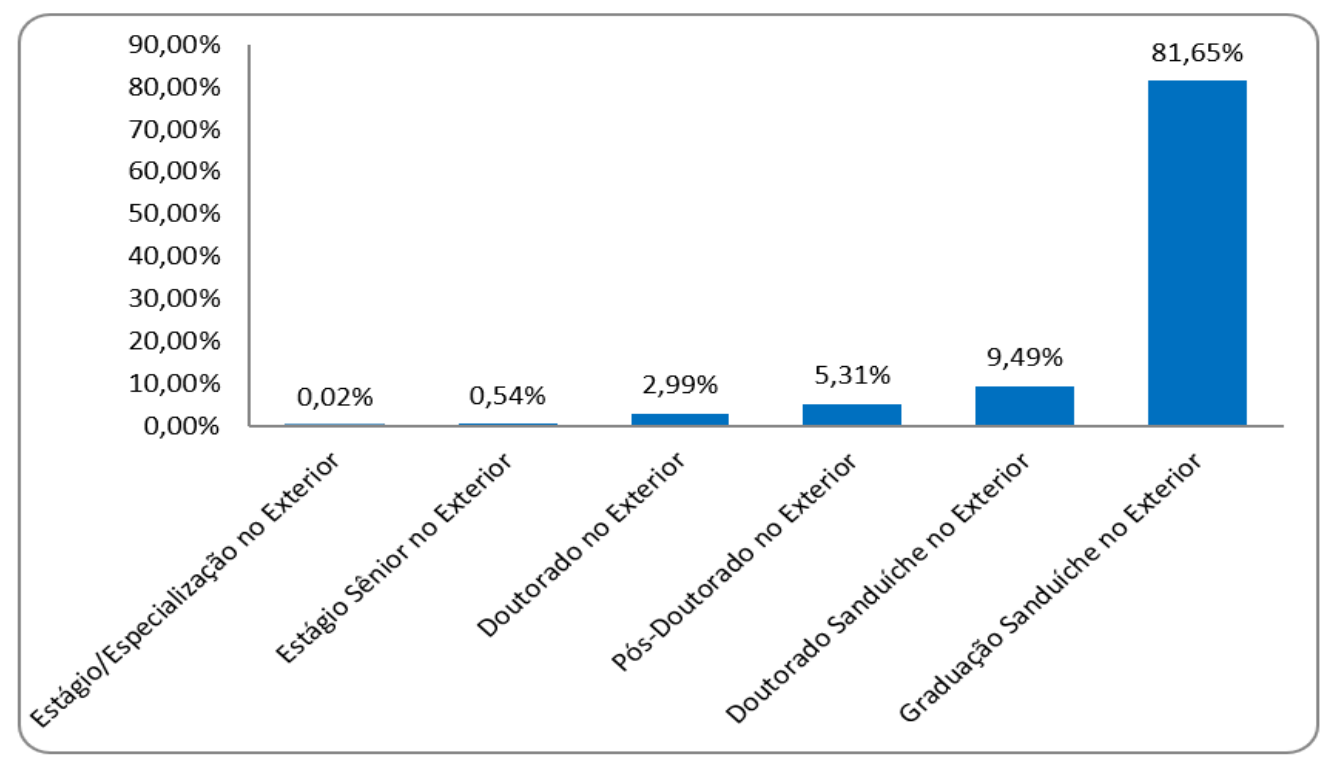

Fonte: CNPq, elaboração SAIAT/SPM, 2013.

\section{Grandes Áreas do Conhecimento e as Relações de Gênero}

Para melhor analisar este Programa pelo ângulo das relações de gênero foi realizada uma classificação das áreas consideradas no Programa e estas foram organizadas, segundo critérios já consagrados pelo CNPq em quatro grandes áreas: Engenharias, Ciências Biológicas e da Saúde; Ciências Exatas e da Terra e Ciência da Computação, agrupadas arbitrariamente da seguinte forma:

Engenharias: Energias Renováveis; Engenharias e demais áreas tecnológicas; Indústria Criativa (referente a produtos e processos para desenvolvimento tecnológico e inovação); Novas Tecnologias de Engenharia Construtiva; Petróleo, Gás e Carvão Mineral; e Tecnologia Mineral. 
Ciências Biológicas e da Saúde: Biodiversidade e Bioprospecção; Biologia, Ciências Biomédicas e da Saúde; Biotecnologia; Ciências do Mar e Fármacos.

Ciências Exatas e da Terra: Ciências Exatas e da Terra; Produção Agrícola Sustentável e Tecnologias de Prevenção e Mitigação de Desastres Naturais.

Ciência da Computação: Computação e Tecnologias da Informação; Formação de Tecnólogos, Nanotecnologia e Novos Materiais e Tecnologia Aeroespacial.

Ao longo deste primeiro ano de funcionamento o programa concedeu 12.635 bolsas (12/2012). Deste total de bolsas, 60 bolsas foram classificadas pelo CNPq em uma categoria denominada como "Não informado".

Estas tiveram a seguinte distribuição: Graduação Sanduíche no Exterior responde por $81,65 \%$ das bolsas concedidas, Doutorado Sanduíche no Exterior por 9,49\%, Pós-Doutorado no Exterior por 5,31\%, Doutorado no Exterior por 2,99\%, Estágio Sênior no Exterior por $0,54 \%$ e Estágio/Especialização no Exterior por $0,02 \%$. Este primeiro ano o programa concedeu, portanto, $12,51 \%$ do total de bolsas que o governo está programando oferecer até o ano de 2015.

Analisando as diversas áreas pela variável gênero observa-se no gráfico 6 que as Engenharias respondem por 50,59\% destas bolsas, seguido das Ciências Biológicas e da Saúde 26,13\%, Ciências Exatas e da Terra com $14,70 \%$, Ciência da Computação com 8,10\% e a categoria "Não informado" com $0,47 \%$. Esta concentração nas áreas de engenharia e computação expressa o foco principal do Programa que se dirige prioritariamente para a formação de pessoal nestas áreas tecnológicas necessário ao futuro desenvolvimento do país e estas são praticamente $60 \%$ da oferta de bolsas do Programa.

GRÁFICO 6

CNPq, Programa Ciência sem Fronteiras, distribuição de bolsas, por área de concentração.

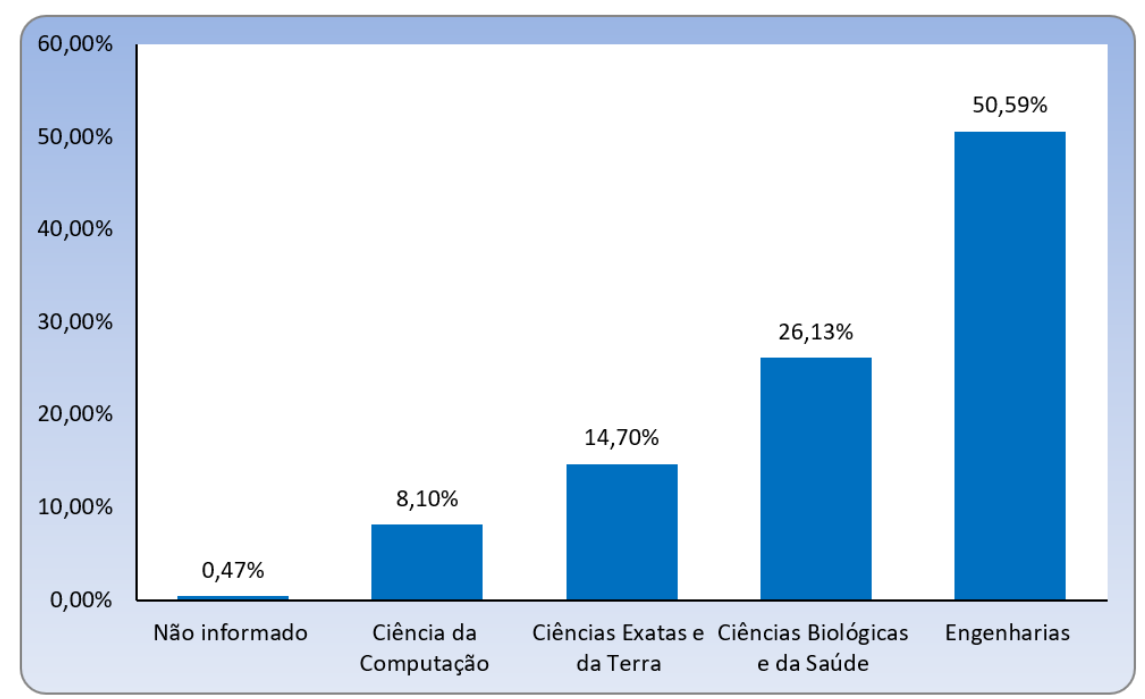


Fonte: CNPq, elaboração SAIAT/SPM, 2013.

Analisando o gráfico 7 pelo prisma das relações de gênero este mostra que na Ciência da Computação elas são 22,46\% das bolsistas, nas Engenharias são 37,84\% e nas Ciências Exatas e da Terra são 45,45\%, mesmo na categoria "Não informado" as mulheres são $60 \%$ e nas Ciências Biológicas e da saúde são $61,93 \%$.

É interessante chamar atenção para o fato que esta distribuição das bolsas concedidas no ano de 2012 não repete a presença das mulheres nos cursos de graduação do Brasil, como demonstram os gráficos anteriores. Aparentemente as mulheres tomaram decisões de participar do Programa numa dinâmica maior do seu peso nos cursos, provavelmente apostando no futuro e numa perspectiva de conseguir uma mais carreira exitosa no futuro quando ingressasse no mercado de trabalho.

GRÁFICO 7

CNPq, Programa Ciência sem Fronteiras, distribuição de bolsas por área de concentração e sexo, 2012.

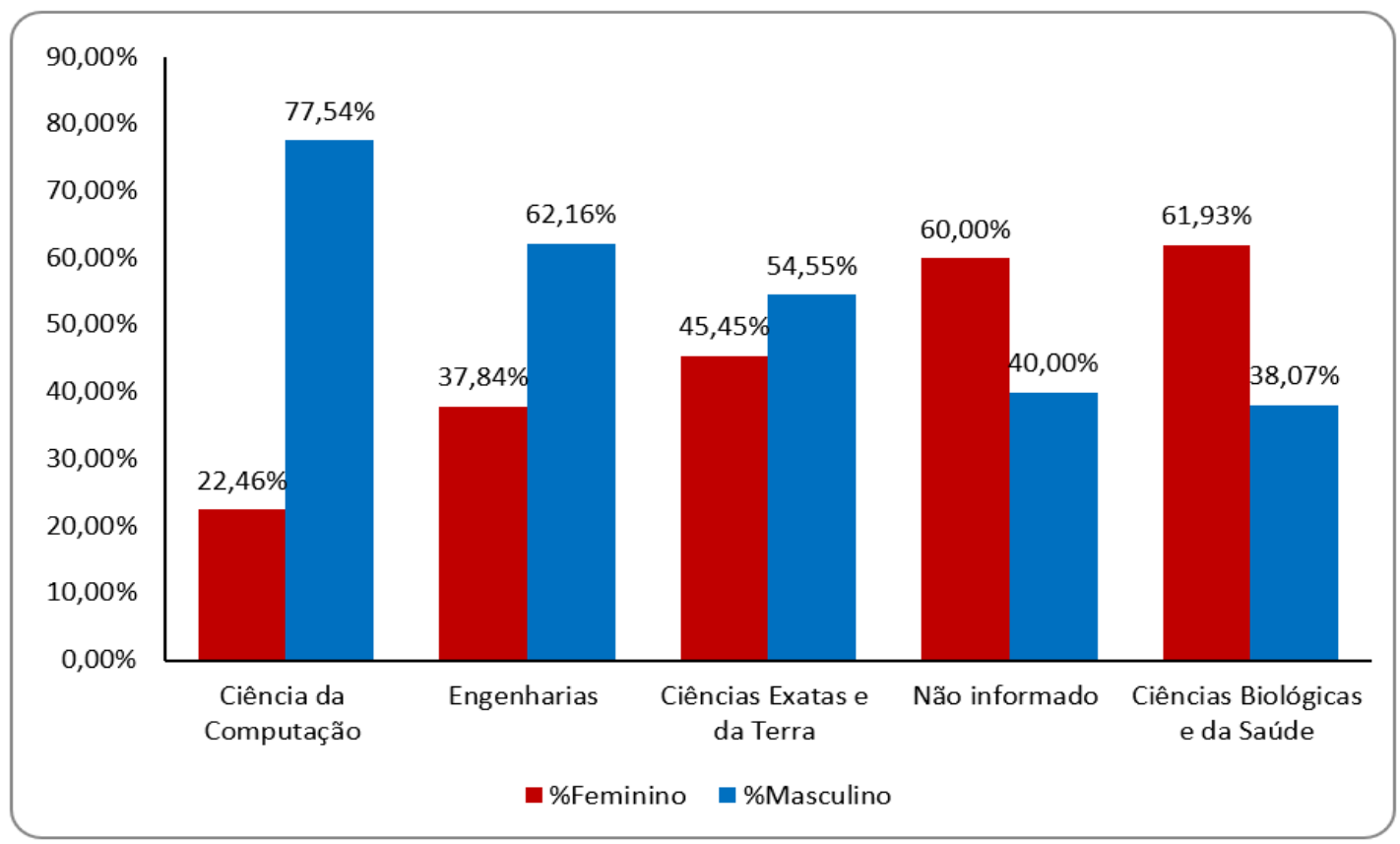

Fonte: Brasília, CNPq, elaboração SAIAT/SPM, 2013.

A forte presença feminina nas áreas biológicas e da saúde não é uma novidade, pois estas são áreas do conhecimento que tem predomínio do sexo feminino, seja nos cursos de graduação e pós-graduação como na própria carreira. Nos cursos de graduação presenciais relativas às Ciências Biológicas e da Saúde, as mulheres respondem por 69\% das matriculas destas áreas, mas no Programa Ciência sem Fronteiras, elas respondem por $62 \%$ das bolsas concedidas, fica, portanto, próxima da sua participação nos cursos universitários. 
Uma nova tendência surge nas áreas das engenharias e tecnológicas. A Ciência da Computação tem $22,46 \%$ de seus bolsistas do sexo feminino, não distante do percentual identificado nos cursos de graduações presenciais que é de $15,30 \%$. Nas Ciências Exatas e da Terra a participação feminina no Programa Ciência sem Fronteiras é de $45,40 \%$ e uma taxa de participação de $26,80 \%$ das matrículas presenciais universitárias do Brasil neste campo disciplinar. Nas engenharias as mulheres são $25 \%$ das matrículas da graduação presenciais e mesmo assim elas são $37,84 \%$ das bolsistas desta área. Estes números permitem fazer uma primeira indagação: as mulheres estão ficando mais arrojadas e lançaram-se neste programa de forma similar ao sexo oposto? Essa atitude indica que elas estão priorizando a escolha da carreira e não a família, como o passado feminino consagrou até esta geração? Como não foi possível fazer o acompanhamento das carreiras destas jovens estudantes a pergunta fica no ar. De qualquer maneira estes dados demonstram que algumas mudanças estavam ocorrendo e a extinção do Programa para os estudantes de graduação em julho de 2016 não permitiu mais aprofundar esta análise ${ }^{5}$.

\section{Reflexões finais}

Este artigo não teve a pretensão de analisar a complexidade que envolve a questão da conciliação entre carreira e família e, sobretudo discutir as escolhas profissionais femininas, apenas levantou a questão a partir dos primeiros dados de um programa recém-criado e rapidamente fechado pelo governo brasileiro no âmbito dos Ministérios da Educação e da Ciência, Tecnologia e Inovação através do Conselho Nacional de Desenvolvimento Científico e Tecnológico (CNPq). Apenas assinalar que mesmo com a participação das ciências biológicas no Programa, o fato das graduações de engenharia terem tido um peso de $50 \%$ nas concessões das bolsas e as mulheres terem sido responsáveis por $44 \%$ das bolsas no ano de 2012 mostra que as estudantes de engenharia foram "provavelmente" bolsistas em uma percentagem superior a sua taxa de participação no curso.

Acreditamos que estes dados embrionários do Programa Ciência sem Fronteiras apontam para uma novidade, que as mulheres que escolheram 0 "novo" nas suas graduações têm uma perspectiva diversa de suas mães e avós em relação ao exercício de suas carreiras profissionais.

\section{Referências}

$5 \quad$ Em 23 de julho de 2016 o Ministro da Educação Mendonça Filho anunciou o encerramento das bolsas para estudantes de graduação alegando falta de recursos e que como desde 2015 não tinha havido mais editais do programa para a graduação sua continuidade seria interrompida. 
BRASIL. A mulher na educação superior brasileira: 1991-2005. Ministério da Educação, Instituto Nacional de Estudos e Pesquisas Educacionais Anísio Teixeira. Brasília, 2007. Disponível em: < www.edudatabrasil.inep.gov.br>

Programa Ciência sem Fronteiras. Ministério da Ciência, Tecnologia e Inovação (MCTI), Conselho Nacional de Desenvolvimento Científico e Tecnológico (CNPq), Diretoria de Engenharias, Ciências Exatas e Humanas e Sociais (DEHS). Dezembro de 2012, tabulação especial.

BRUSCHINI, C. Brasil: la calidad del empeo de las mujeres. Continuidades y cambios. In: VALENZUELA, M.E.; REINECKE, G., Más y mejores empleos para las mujeres? Santiago, Chile: OIT, 2000.

LIMA, Betina S. Quando o amor amarra: reflexões sobre as relações afetivas e a carreira científica. Revista Gênero, Niterói: v. 12, n. 1, 2emestre de 2012.

MARUANI, Margaret; ROGERAL, Chantal; TORNS, Teresa (dirs). Las nuevas fronteras de la igualdade: hombres y mujeres en el mercado de trabajo.

Paris/Madrid: Éditions La Découverte et Syros; Barcelona: Icaria Editorial, 1998.

MELO, Hildete Pereira de; LASTRES, H.M.; MARQUES, T.C.de N. Gênero no Sistema de Ciência, Tecnologia e Inovação no Brasil. Revista Gênero. Niterói, Universidade Federal Fluminense, v. 4, n. 2, 1ํㅗ semestre de 2004.

MELO, Hildete Pereira de. Gênero e Perspectiva regional na Educação Superior Brasileira. In: RISTOFF, D. (et al). Gênero e Indicadores da Educação Superior Brasileira. Brasília/DF: Instituto Nacional de Estudos e Pesquisas Educacionais Anísio Teixeira, 2008.

SCHIEBINGER, Londa. O Feminismo mudou a ciência? Bauru, SP: EDUSC, 2001. 